\title{
Culturas científicas sobre os oceanos na historiografia das ciências no Brasil
}

\section{Scientific Cultures about Oceans \\ in the Historiography of Science in Brazil}

\section{Maria Margaret LOPES*}

RESUmo $\mathrm{O}$ artigo menciona iniciativas relacionadas à construção das culturas científicas sobre os oceanos no Brasil, dos meados do século XIX à primeira metade do século XX. Identificando os oceanos como espaços de produção de conhecimentos, aborda como os oceanos, desde suas águas, sua biodiversidade, suas ilhas, profundidades, tornaram-se objetos específicos de pesquisas. Nesses processos, agentes e agências se forjaram no contexto de complexos campos científicos interdisciplinares, que se modificaram internacionalmente e nas instituições brasileiras. Dialogando com conhecidos autores da História das Ciências, o artigo se organiza em subtemas que se intercruzam, como expedições oceânicas, publicações e instituições. Conclui destacando a necessidade de reflexão historiográfica sobre os atuais empreendimentos globais de exploração dos recursos minerais do mar, especialmente nestes anos em que a ONU celebra a Década das Ciências dos Oceanos.

Palavras-Chave expedições oceânicas, institutos oceanográficos, nódulos polimetálicos

\footnotetext{
* https://orcid.org/0000-0002-9803-8378

Universidade de São Paulo, Museu de Arqueologia e Etnologia (MAE/PPGMUS) Av. Prof. Almeida Prado, 1466, Butantã, 05508-070, São Paulo, SP, Brasil mariamargaretlopes@gmail.com
} 
Abstract This article mentions some initiatives related to the construction of scientific cultures about the oceans in Brazil, from the midi$19^{\text {th }}$ century to the first half of the $20^{\text {th }}$ century. It characterizes oceans as spaces of knowledge production, addressing how the oceans, with its waters, biodiversity, islands, and depths, became specific research objects. In these processes, agents and agencies were forged in the context of complex interdisciplinary scientific fields, which were modified both internationally and in Brazilian institutions. Dialoguing with wellknown authors of the History of Sciences, the article is organized in intersecting subthemes, such as ocean expeditions, publications, and institutions. It concludes highlighting the need for historiographical reflection on the current global undertakings to explore the mineral resources of the sea, especially in the years between 2021 and 2030, in which the UN celebrates the Decade of Ocean Sciences.

Keywords Deep Sea Expeditions, Oceanographic Institutes, Polymetallic Nodules

\section{INTRODUÇÃo}

Há séculos, os oceanos ocupam um papel central na vida da humanidade. Hoje, os oceanos estão completamente integrados aos estudos e debates sobre as alterações climáticas globais, conservação da biodiversidade e preservação da própria vida no planeta. As atuais políticas sobre extensão de plataformas continentais e reivindicações de direitos e licenças de exploração de mares profundos, no Brasil e em outros países, vão além de questões de estratégias político-militares, exploração petrolífera, utilização do mar para a produção de energia eólica, solar e das ondas, ocupação do mar por resorts e extensão de cidades. Entre as principais expectativas dessas propostas está o que é vendido como a última fronteira a ser explorada: os recursos das profundidades oceânicas, crostas e nódulos polimetálicos, veios hidrotermais, organismos oceânicos e biomoléculas de microrganismos (BARRIGA, 2013). No caso brasileiro, a Marinha cunhou a expressão, que sugere diversas 
interpretações - Amazônia Azul, ${ }^{1}$ como uma analogia aos recursos (ou à exploração) da enorme região florestal, para se referir à extensão equivalente do território atlântico incorporada na ampliação da plataforma continental brasileira.

Também no Brasil, as investigações técnico-científicas sobre os oceanos alcançam, hoje em dia, um grau de sofisticação e complexidade que não está sendo acompanhado na mesma medida pela produção historiográfica das ciências e tecnologias. A história das ciências dos oceanos tem sido bastante negligenciada na historiografia brasileira (HEIZER; LOPES; GARCIA, 2014). Retomamos neste artigo apenas aspectos gerais de algumas iniciativas situadas, locais, relacionadas às ciências dos oceanos no país, como um contributo para novas pesquisas, para enfrentarmos os desafios atuais e os que temos pela frente.

Para pensarmos histórias mais globais sobre a produção e circulação de conhecimentos sobre os oceanos, de um ponto de vista da História das Ciências no país, partimos de alguns aspectos da construção das culturas científicas dos oceanos em suas intersecções com ideias de conhecidos autores da História das ciências. Já há alguns anos, as ideias de circulação (SECORD, 2004) que perpassam este artigo têm servido como um forte contraponto às perspectivas unidirecionais ou às bipolarizações das antigas propostas difusionistas em História das Ciências. Lissa Roberts (2009) também buscou retirar da ideia de "circulação" sua conotação imperial e suas reivindicações de neutralidade associadas às ideias de progresso e de verdade universal. Apontou também a importância do local para uma melhor compreensão sobre os processos de circulação e transferência de conhecimentos, tecnologias e expertises no contexto de redes internacionais marcadas por relações assimétricas, dependentes de intercâmbios econômicos, de trocas de favores, mecenato, amizade, obrigação.

Mais significativas têm sido as histórias e descrições densas sobre detalhes específicos de situações contingenciais que, privilegiando a

1 Ver o site da Marinha brasileira. AMAZÔNIA Azul. In: Marinha do Brasil. Disponível em: $<$ https://www.mar.mil.br/hotsites/amazonia_azul/artigos.html>. Acesso em: 09 fev. 2021. 
localidade da produção do conhecimento em circulação, podem transgredir escalas, lugares e territórios (RAJ, 2013). No caso deste artigo, os conhecimentos sobre os mares, criando ou utilizando redes de cooperação e disputas, aventuram-se em espaços com fronteiras incertas ou em movimento. Para uma historiografia abrangente e global das ciências dos oceanos, partindo de tais ideias e focando em localidades, ações conjunturais e contingentes, consideramos importante ter uma ideia sobre o que aconteceu em cada país, ou mesmo e principalmente, o que ocorreu em instituições ou locais específicos, ou ainda nas atividades de agentes particulares.

Sem qualquer intenção de traçar quadros completos ou mais abrangentes da história das ciências dos oceanos no Brasil - que ainda estão por ser feitos -, este artigo é acima de tudo um convite a novas pesquisas. Seguindo alguns bem conhecidos autores da História das Ciências, organizamos as considerações que se seguem elencando apenas algumas situações, problematizações e sugestões para futuras pesquisas, já que somente um esforço conjunto e mais amplo poderia contribuir para avançarmos perspectivas de detalhe, para compor panoramas mais abrangentes para uma História das Ciências dos Oceanos no país.

\section{“TORNAR Visíveis": EXPEDIÇões, Disciplinas, Publicações}

As expedições oceânicas da segunda metade do século XIX trouxeram transformações dramáticas de como os oceanos eram percebidos. Os oceanos tornaram-se lugares a serem explorados e foram representados em uma escala de trabalho completamente nova. Tornaram-se espaços que podiam ser controlados, por novas formulações sobre teorias, por novos avanços científicos e tecnológicos (ROZWADOWSKI, 2008). Para Norton Wise (2006), muito do que se faz em História das Ciências poderia ser descrito em termos de "tornar visíveis" novos objetos ou objetos familiares de uma maneira inovadora. Ele não se referia aos oceanos, mas o que os exploradores e estudiosos dos oceanos fizeram desde então, que foi precisamente tornar os oceanos visíveis e de novas maneiras. 
As expedições oceânicas passaram a representar as tentativas mais sistemáticas para medições e mapeamentos das profundidades dos oceanos. As teorias azóicas de Edward Forbes (1815-1854) sobre a inexistência de vida nas grandes profundidades oceânicas foram completamente abandonadas. Coleções, mapas, relatórios e trabalhos organizados por especialistas a partir das amostras e de dados e mais dados acumulados por numerosas expedições e, especialmente, desde a Challenger (1872-1876), acrescentaram novos campos e subcampos de conhecimentos em todas as áreas disciplinares. A Challenger Expedition é bem conhecida. Realizada com o apoio da Royal Society e da Marinha Britânica, John Murray (1841-1914) - o naturalista da Challenger, que se tornaria uma autoridade líder em estudos oceânicos - coordenou a publicação dos seus 50 volumes durante quase vinte anos, com os resultados das milhares de coleções zoológicas, botânicas, geológicas e amostras de águas coletadas, que foram examinadas pelos principais especialistas do período. ${ }^{2}$

Apresentada como o marco inicial da moderna Oceanografia, a Challenger Expedition representa, sem dúvida, um ponto de inflexão na história da Oceanografia, como Margaret Deacon (1997) apontou em seu estudo clássico. Há uma vasta bibliografia sobre as várias expedições oceânicas até as primeiras décadas do século XX. Estudos recentes na Nova Zelândia e no Brasil, por exemplo, buscam tratar agora suas narrativas - até então limitadas em grande parte às viagens dos navios no mar e aos seus legados dos novos dados científicos -, do ponto de vista dos impactos locais dessas viagens. Esses impactos não se limitaram à circulação das novas inovações divulgadas. As menções à Challenger e a outras expedições foram utilizadas como argumentos de autoridade em

2 MURRAY, John. Report on the Scientific Results of the Voyage of H.M.S. Challenger During the Years 1873-76 under the Command of Captain George S. Nares and the late Captain Frank Tourle Thomson. Prepared under the Superintendence of the late Sir C. Wyville Thomson and Now of John Murray. Published by Order of Her Majesty's Government. Hanover: David C. Bossard, 2004. Disponível em: <http://www.19thcenturyscience.org/HMSC/HMSC-INDEX/ index-illustrated.htm>. Acesso em: 09 fev. 2021. 
disputas científicas e mesmo políticas nos diferentes lugares do mundo em que esses navios aportaram (ZUROSKI, 2017; LOPES, 2018).

Outras abordagens da História das Ciências já identificaram períodos anteriores de interesse mais sistemático na investigação dos oceanos, pelo menos a partir do final do século XVIII. Baleeiros, pescadores, pessoas que viviam na costa, naturalistas, oficiais e marinheiros realizaram uma série de observações e avanços técnicos para a medição sistemática das profundidades dos oceanos, direção de correntes, variação de temperatura das águas, incluindo novos métodos e instrumentos para coleta de amostras. Nesses processos, evidentemente desde o período colonial, os mares, as ilhas e a costa brasileira mereceram a atenção dos colonizadores para a construção de portos, fortalezas, medições de profundidades das águas litorâneas, caça de baleias e pesca. Ao longo do XIX, foram diversas as iniciativas da marinha brasileira, a exemplo das ações mais sistemáticas de implantação de serviços hidrográficos na década de 1860 , voltados à delimitação da plataforma continental para instalação dos cabos submarinos de suporte às redes telegráficas litorâneas.

Nas páginas de publicações locais como a Revista do Instituto Polytechnico Brazileiro, o Boletim da Sociedade de Geographia do Rio de Janeiro, Arquivos do Museu Nacional, A Voz do Mar ${ }^{3}$ e particularmente na Revista Marítima Brasileira, órgão oficioso da Marinha desde 1881, as culturas científicas voltadas para a Hidrografia e Oceanografia tomaram forma, no país, envolvendo uma complexidade de agentes. Daí surgem nomes a serem mais conhecidos e explorados e listagens de publicações que permitem identificar a produção existente sobre estudos relacionados aos oceanos em maiores proporções do que muitas vezes se supõe.

3 A Voz do Mar iniciada em novembro de 1921, foi a primeira revista publicada no país, especialmente dedicada às atividades e legislação pesqueiras. Iniciativa da Marinha, a revista se apresentava como órgão oficial da Confederação Geral dos Pescadores do Brasil. Tinha como público alvo as colônias de pescadores que foram organizadas à época. A Hemeroteca Digital da Biblioteca Nacional disponibiliza a Revista até 1957. A VOZ DO MAR, Rio de Janeiro, n. 1, 19 nov. 1921. Disponível em: <http://memoria.bn.br/DocReader/docreader.aspx? $\mathrm{bib}=183660$ \&pasta=ano\%20192\&pesq=\&pagfis=1>. Acesso: 9 fev. 2021. Ver CALLOU, 1995. 
E talvez caiba questionar o Barão de Teffé - Antonio Luiz Hoonholtz (1837-1931) -, que considerou a história da Hidrografia no país "de pouco interesse e pouco instrutiva", uma vez que poucos oficiais da Marinha haviam se dedicado à produção científica, à exceção, segundo o autor, da atuação do conhecido capitão-de-fragata Manoel Antonio Vital de Oliveira (1829-1867) nessa trajetória. No entanto, o Barão de Teffé não deixou de se referir à existência da obrigatoriedade do ensino de Hidrografia para os guardas-marinha desde 1859, às instruções e normatizações para o Serviço Hidrográfico do Império desde 1862, sua própria organização da Repartição Hidrográfica, do Ministério da Marinha, cuja direção assumiu em 1876 e cujos arquivos mantinham "perfeitamente acondicionados e catalogados, nada menos do que 17.000 exemplares de cartas hidrográficas, além de inúmeros outros mapas e documentos" (SECÇÃO, 1888, p. 151-152). Alguns autores já consideram as primeiras iniciativas mais sistemáticas de pesquisas marítimas no país, justamente a implantação dos serviços hidrográficos da década de 1860, devidos a Vital de Oliveira e ao Barão de Teffé e as tentativas de delimitação da plataforma continental pelas expedições de 1861 a 1866, comandadas por Amedée Mouchez (1821-1892), que posteriormente seria diretor do Observatório Astronômico de Paris (AB'SABER, 1979-1980).

Para o início do século XX, as produções se avolumam. Os oceanos possibilitaram o surgimento de novas áreas de culturas científicas. A Hidrografia compartilhou espaços com a Oceanografia. A Geologia, a Biologia e a Geografia começariam a acrescentar "Marinha" a suas novas especialidades e a evidenciar a circulação de conhecimentos sobre os oceanos. No país, as menções aos autores referenciais, particularmente franceses, estão presentes nas teses defendidas pelos alunos da Escola Naval. Estão presentes em artigos publicados na Revista Marítima Brasileira, a exemplo do artigo do $1^{\circ}$ tenente Mario R. da Silva que, em 1902, apoiava-se nas obras Océanographie (statique) de 1890 e Océanographie (dynamique) de 1896, do conhecido naturalista e hidrógrafo francês Julien Thoulet (1843-1936) para entender, por um lado, o relevo submarino, composição química e propriedades físicas das águas e, por outro, os fenômenos resultantes dos movimentos dos mares. José Augusto 
Vinhaes, um dos mais profícuos intelectuais da Marinha, redigia em 1905 seu compêndio de Oceanografia, além das demais obras como o Aspecto Litorâneo de 1911, Correntes oceânicas de 1922 e Hidrografia e evolução marítima de 1925, entre outras obras que se sucederiam nos anos seguintes e estão à espera de maiores análises (LOPES, 2017).

Livros didáticos também dedicaram amplos capítulos aos processos climáticos e aspectos físicos e geológicos dos oceanos, como o Geologia elementar preparada com referencia especial aos Estudantes Brazileiros e à Geologia do Brasil, de Branner, publicado em 1915. ${ }^{4}$ As coleções e obras de Alípio de Miranda Ribeiro (1874-1939) voltadas para a Ictiologia, para o conhecimento das espécies de peixes e crustáceos do Atlântico, marcariam praticamente todos os volumes dos Arquivos do Museu Nacional nas primeiras décadas do século XX. Considerado oum primeiro ictiólogo brasileiro, embora sem formação específica, Alipio Miranda Ribeiro sistematizou em uma série de volumes dos Arquivos de 1907 a 1918 - seus levantamentos das coleções do Museu Nacional. ${ }^{5}$

E ainda na ausência de instituições específicas de investigação hidrográfica e oceanográfica no país, o Museu Nacional do Rio de Janeiro foi um dos responsáveis pela consolidação desses estudos. Em 1916, com o apoio da Marinha, a bordo do Barroso, o Museu realizou uma grande expedição científica à Ilha da Trindade, um território disputado pela Inglaterra desde 1700, quando Edmond Halley - que se tornaria o famoso astrônomo -, tomou posse da ilha para a Inglaterra. Inúmeras expedições de diversos países e também da Marinha do Brasil, estiveram sucessivamente na ilha. Ocupada para a instalação de cabos

4 John Casper Branner (1850-1922) que participou das expedições de Hartt e Agassiz ao Brasil, no século XIX, coordenou a Stanford Expedition ao Nordeste em 1911, e publicou extensivamente sobre o país, desde os recifes de corais aos estudos das ilhas oceânicas, às possibilidades de ocorrência de petróleo (FIGUEIRÔA, 2016).

5 Grande parte dessas coleções e as que se somaram até hoje, com suas informações digitalizadas, estão preservadas em um edifício próprio não atingido pelo fogo de 2019. MUSEU NACIONAL, Universidade Federal do Rio de Janeiro (UFRJ). In: GBIF Integrated Publishing Toolkit. Disponível em: <https://ipt.sibbr.gov.br/mnrj/resource?r=mnrj_ictiologia $>$. Acesso em: 09 fev. 2021. 
submarinos em 1895, os ingleses reclamaram a posse da ilha da Trindade, argumentando também as suas sucessivas ocupações anteriores, levando o Brasil a uma extensa disputa diplomática com a Inglaterra, mediada por Portugal (ALVES, 2001). A manutenção do controle da soberania nacional através da investigação científica foi o argumento utilizado pelo Museu Nacional do Rio de Janeiro nessa primeira grande expedição oceanográfica, cujos dados e coleções armazenados pelos preparadores do Museu foram classificados e publicados por diversos especialistas nacionais. ${ }^{6}$

Desde a Challenger nenhuma dessas expedições pôde ser caracterizada como de ciência pura, como advertiu Harold Burstyn (1975) em seus trabalhos referenciais sobre a história da Oceanografia. Não se pode ignorar que um dos principais interesses de todas as várias expedições oceânicas era não só o mapeamento potencial da pesca comercial em todo o mundo, mas também o estabelecimento de rotas de navegação mais seguras e a garantia do controle dos litorais, dos mares e de suas profundidades não só por questões políticas estratégicas, como também para exploração econômica. ${ }^{7}$

Na década de 1920, a partir das tecnologias submarinas desenvolvidas para a Primeira Guerra Mundial, as sondagens acústicas substituíram os tradicionais métodos de medidas de profundidades dos oceanos baseados na linha e peso de chumbo e tornaram-se indicadores mais rápidos e confiáveis. A Deutsche Atlantik Expedition, conhecida como Expedição Meteor, amplamente noticiada pelos jornais brasileiros, foi a primeira expedição a aplicar a nova tecnologia de sondagem acústica

6 A bibliografia sobre a ilha da Trindade é imensa ao longo do século XIX e XX. Para históricos com diferentes abordagens e sobre várias das expedições, em diferentes períodos que se dirigiram à Trindade, ver, além de Bruno Lobo (1919), vários outros autores como Duarte e Horta (2012) e, especialmente, os Boletins do Instituto Oceanográfico da USP. Atualmente existem inúmeros projetos com apoio do CNPq e agências de fomento locais para investigação das ilhas oceânicas brasileiras.

7 Burstyn (1975), um dos autores fundacionais da História dos Oceanos, destaca esses aspectos em sua análise sobre o enriquecimento pessoal de John Murray, resultado do seu interesse científico pelos processos de formação dos recifes de coral que o levaram à exploração de fosfato de Christmans Island, que seria incorporada ao governo britânico em 1888. 
para mapear o assoalho do Atlântico Sul entre 1925 a 1927. Acompanhando esses processos, Alberto Betim Paes Leme (1883-1938), em sua obra História Física da Terra (Vista por quem a estudou do Brasil), de 1924 (FIGUEIRÔA, 2012), refere-se inúmeras vezes aos dados das Expedições Challenger e Meteor relativos ao país, às ilhas e aos diferentes ambientes de sedimentação no Atlântico sul - dos mares rasos à composição química das 'argilas abissais' de cor vermelha do Atlântico, mapeadas pela primeira vez pela Challenger, e à identificação das cadeias de montanhas em meio ao Atlântico pela Meteor, argumento que seria utilizado em suas discussões sobre a teoria da deriva continental (PAES LEME, 1943). As investigações sobre os assoalhos oceânicos foram fundamentais para as teorias da deriva continental de Alfred Wegener (1880-1930) e Frank Taylor (1860-1938), ao longo de toda a primeira metade do século XX.

$\mathrm{Na}$ ausência de cursos específicos no país - anteriormente à organização das Universidades na década de 1930 -, além das contribuições da Marinha, referências sobre o ensino de Hidrografia e/ ou Oceanografia surgem de maneira dispersa. Roberto Seidl ministrou uma aula inaugural na cadeira de Oceanografia do Curso Superior Livre de Geografia, realizada em 21 de setembro de 1927. Aí a Oceanografia era caracterizada como uma ciência nova em formação, e outro de seus pioneiros, Alphonse Berget (1860-1933) - o também conhecido professor de Oceanografia Física do Instituto Oceanográfico de Paris a definia como "o estudo geométrico, físico e biológico do mar" (SEIDL, 1926-1927, p. 105). Tais estudos não poderiam ser realizados por um único indivíduo e a prática necessariamente pressupunha o trabalho cooperativo de indivíduos, instituições e países, dada as próprias dimensões do objeto de estudo: os oceanos.

8 Roberto Seidl teria ministrado 6 aulas no curso de 1927. No artigo de Seidl (1926-1927), o autor menciona que Gustavo Hasselmann, "incansável propulsor do estudo do mar entre nós", teria fundado em fins de 1924 a Sociedade Brasileira de Piscicultura e Oceanografia, com o apoio da Diretoria da Pesca. A Revista A Voz do Mar publica algumas referências a essa sociedade e identifica Gustavo Hasselmann como professor catedrático de Zoologia Agrícola e Hidrologia Aplicada da Escola Superior de Agricultura, falecido em 1930. 
Para o "homem do mar" como se apresentava Eurico Costa, capitão de corveta, em seu discurso de posse como sócio efetivo da Sociedade de Geografia, em 3 de setembro de 1936, a evolução da Geografia se associava ao sucesso das navegações e aos avanços da ciência náutica. Aos marinheiros atribuía a maior contribuição à constituição da Oceanografia, tanto na prática como na teoria. As grandes expedições haviam revelado as profundezas abissais, as determinações das longitudes. A importância prática da Oceanografia era inquestionável para a pesca e telegrafia submarina. Do ponto de vista teórico, sua referência indiscutível seria Thoulet, a quem atribuía a frase "A Geologia é a Oceanografia do passado" para explicar que não se tratava, então, de tornar a Oceanografia uma disciplina individualizada, mas sim inseri-la em quadros geográficos, atribuindo à ciência do mar o caráter sintético e global integrador do conhecimento total da Terra (COSTA, 1936, p. 167). Para o comandante Armando Pinna, em seu Curso de Oceanografia, Pesca e Psicultura de 1938, a oceanografia, "ciência que estuda os oceanos em todos seus aspectos", só poderia ser entendida em todas suas dimensões se incorporadas a pesca e a psicultura, temáticas que ocupam a maior parte de sua obra (PINNA, 1938, p. 7).

Tributários de várias tradições, culturas, práticas e áreas de conhecimento, os estudos sobre os oceanos conferiram, desde seus inícios, atenções especiais à pesca. Como por todo o mundo, também no país, nessas primeiras décadas se ampliaram os estudos sobre melhoramentos da pesca. Visando medidas econômicas para incentivo às indústrias da pesca, saneamento das comunidades pesqueiras litorâneas, organização de colônias de pescadores e busca de quadros para a Marinha, a expedição a bordo do José Bonifácio, conduzida pelo capitão de fragata Frederico Villar, percorreu o litoral brasileiro de 1919 a 1923 (BENTES FILHO, 2018). ${ }^{9}$ Em todos esses processos em que a pesca

9 O contra-almirante Frederico Villar (1950), em longo artigo, fez um balanço dessas iniciativas, as quais considerou bem sucedidas em função dos trabalhos realizados pelas missões do cruzador José Bonifácio desde 1912 e entre 1919 e 1923, quando o comandou, embora fossem desarticuladas nos anos seguintes. 
assumiu importância crucial, destacava-se desde pelo menos 1911 a importância da necessidade de organização de um serviço que centralizasse a pesca no país e/ou a criação de um instituto oceanográfico, a exemplo dos que já existiam desde o final do XIX em vários países.

\section{“EXPERIMENTOS INFRAESTRUTURAIS": INSTITUIÇÕES PARA AS CIÊNCIAS DOS OCEANOS}

A demanda pela criação de um instituto voltado para políticas específicas para a pesca e para estudos oceanográficos, para ensino e pesquisa, estiveram em pauta no país desde o final do século XIX. Tratava-se de reivindicação antiga da oficialidade naval, temática reiteradamente retomada na Revista Marítima Brasileira. Registros fragmentados, dispersos nos jornais diários, nas publicações anteriormente citadas, em artigos de periódicos científicos que mencionam instituições existentes, possibilitam compor indícios das iniciativas concretizadas ou não, bem sucedidas ou não em torno dessas reivindicações e iniciativas.

Ainda não temos para o Brasil ou mesmo para América Latina estudos com uma longa tradição historiográfica, desde o extenso levantamento de Kofoid (1910), que elencou aspectos da história e dos principais objetivos das instituições europeias voltadas para os estudos dos oceanos. ${ }^{10}$ Mas em quaisquer das referências a essas demandas ou instituições também no país, é sem dúvida a Estação Zoológica de Nápoles, organizada em 1872 - atual Stazione Zoologica Anton Dohrn, em referência ao seu primeiro diretor -, que inspiraria os laboratórios marinhos em todo o mundo, seguida em anos posteriores por outras instituições modelares até hoje, como são a Scripps Institution of Oceanography na California, cujas origens remontam a 1905, ou a Woods Hole Oceanographic Institution, criada nos anos 1930, no litoral atlântico dos Estados Unidos.

10 A título de exemplo de bibliografías fundacionais sobre instituições de pesquisas sobre os oceanos, ver os Proceedings dos Congressos Internacionais de História da Oceanografia, desde 1966, quando se realizou o primeiro congresso em Mônaco (BENSON; REHBOCK, 2002). 
A impressionante bibliografia sobre a Estação Zoológica de Nápoles aponta a importância dessa instituição em suas primeiras décadas de funcionamento, como um local ideal para a circulação de ideias e práticas científicas, para onde todos os especialistas em Zoologia marinha queriam ir, para a partir de uma experiência significativa seguir em suas carreiras científicas. Os arquivos da Estação Zoológica de Nápoles testemunham o grau de internacionalização da instituição, suas redes de correspondentes e intercâmbios de informações. Hermann von Ihering (1850-1930), especialista em moluscos e diretor do Museu Paulista, no início do século XX (LOPES; PODGORNY, 2014), atestava a importância de seus estágios de formação e pesquisas na Estação de Nápoles, que lhe possibilitaram produzir os inúmeros estudos que fundamentaram a sua história sobre as origens do Oceano Atlântico. ${ }^{11}$

De fato, nos laboratórios marinhos, apesar da sua localização à beira-mar, não foi só o ambiente natural, mas os hábitos e costumes culturais que moldaram firmemente as práticas oceânicas, como Robert Kohler já discutiu. Kohler propôs entender a construção desses laboratórios marinhos inserida em um movimento de retomada de uma nova História Natural, nas práticas e ensino da Biologia na transição para o século XX, em reação aos excessos dos estudos da morfologia de laboratório. Tratava-se de combinar estudos experimentais e de campo, buscando uma cultura mais integrada para o futuro das subdisciplinas da Biologia. A Estação Zoológica de Nápoles é a mais antiga e mais famosa dos 'experimentos infra-estruturais' que Robert Kohler caracterizou como instituições construídas em locais naturais para tentar combinar trabalho laboratorial e de campo (KOHLER, 2002, p. 44).

Para além dos locais específicos de 'esforço científico', nas palavras de Livingstone (2003), desde finais do século XIX as discussões sobre os oceanos invadiram os mais diversos espaços dos congressos hidrográficos, geográficos, geológicos, zoológicos e de Medicina, que desde

11 Com o suporte do projeto de pesquisa CNPq 2015-2018, “Oceanos: capítulos estratégicos na história das ciências geológicas (1870-1950)", foi possível levantar a correspondência de H. von Ihering nos arquivos da Estação Zoológica de Nápoles, em 2017. 
então consolidaram as redes de investigadores envolvidos nos estudos do mar. ${ }^{12}$ No contexto internacional de regulamentação da pesca, países do Norte europeu organizaram, em 1902, o Conselho Internacional para a Exploração do Mar que, até hoje, tem um papel importante na história das ciências dos oceanos e nas atividades pesqueiras (ROZWADOWSKI, 2002; SVANSSON, 2010). ${ }^{13}$

No caso brasileiro, a proposta de organização de um Instituto Oceanográfico esteve em pauta sistematicamente pelo menos desde 1911. A proposta inicial sugeria um organismo central para os serviços pesqueiros e para estudos sobre os problemas científicos e administrativos da atividade pesqueira. Mas então teria sido criada apenas a Inspetoria de Pesca, que teria funcionado por alguns anos na Praia Vermelha a partir de 1912, no Ministério da Agricultura, sob a direção de Alipio Miranda Ribeiro. Em 1936, Saldanha da Gama dá conta das atividades do Serviço Hidrográfico da Marinha, que já estaria em funcionamento desde 1931, quando se criou a especialidade Hidrografia para os oficiais da Marinha. O Serviço responsável pelas cartas náuticas e controle de navegação executava inúmeros trabalhos que poderiam servir de base para as investigações oceânicas (FROTA, 1936, p. 169-178). ${ }^{14}$ Mas a demanda pela criação de institutos de estudos oceanográficos, ensino e políticas específicas para a pesca continuou reiteradamente retomada na Revista Marítima Brasileira. De fato, ao longo de toda a década de 1930,

12 A título de exemplos, no $1^{\circ}$ Congresso Brasileiro de Geografia de 1910, em cuja programação havia um passeio marítimo a algumas ilhas do litoral do Rio de Janeiro, oficiais da Marinha se dividiam entre as comissões 4 - Hidrografia e 5 - Oceanografia. Na comissão de Hidrografia foram lidos, entre outros trabalhos sobre Hidrografia Marítima, "A ribeira de Iguape" de Ricardo Krone. Entre as conclusões da comissão de Oceanografia, sobre o amplo debate em torno das teorias das correntes marítimas, os participantes consideraram não haver até então nenhuma teoria que explicasse exatamente suas ocorrências. Em Portugal, a proposta de criação de uma Estação de Biologia Marítima, associada à organização da Sociedade Portuguesa de Ciências Naturais, foi apresentada por congressistas alemães com base nas suas experiências na Estação Biológica de Helgoland, no $15^{\circ}$ Congresso Internacional de Medicina em Lisboa, em 1906 (LOPES; NUNES; PINA, 2012).

13 Home. In: ICES/CIEM. Disponível em: < https://www.ices.dk/ > Acesso em: 09 fev. 2021.

14 Fernando Saldanha da Gama Frota, capitão tenente fez essa comunicação na Sociedade de Geografia em 3 de setembro de 1936. 
a proposta de organização de um Instituto Oceanográfico Brasileiro esteve na ordem do dia e notícias sobre essas iniciativas na Sociedade de Geografia, no Clube Naval, eram divulgadas pelos jornais diários. A proposta inseria-se, no caso brasileiro, como também em outros países, no contexto das iniciativas e dinamização da atividade pesqueira.

O Instituto de Oceanografia e Ictiologia foi finalmente criado em 1935. O Instituto tinha um vasto programa de investigação e realizou expedições em vários locais ao longo da costa e ilhas brasileiras e particularmente em torno do Rio de Janeiro. Para além das viagens científicas e de interesse para a Marinha, o Instituto encorajou a criação de aquários e museus em escolas e cursos de pesca e oceanografia para professores do Rio de Janeiro como parte de projetos para estimular a indústria pesqueira, para consumo interno e exportação, mas teria enfrentado inúmeras dificuldades. O Instituto de Oceanografia do país, fundado no Clube Naval e em funcionamento nos anos de 1940, para Frederico Villar, um dos proponentes da iniciativa, não teria passado "de um projeto sem o devido alento" até os anos de $1950 .{ }^{15}$ Associados ou não ao Instituto, diversos artigos científicos registram a atuação conjunta em investigações, especialmente na Baía da Guanabara, de pesquisadores do Museu Nacional, da Marinha, da Sociedade de Geografia, da Academia Brasileira de Ciências, da estação de Hidrobiologia do Instituto Oswaldo $\mathrm{Cruz}^{16}$ e das universidades recém-criadas no país. Nesses anos, a Universidade de São Paulo, organizada em 1934, inclusive já tinha um pequeno laboratório de Biologia Marinha no litoral do Estado de São Paulo para aulas dos cursos de Biologia.

Desde os anos 1940, devido aos interesses de exploração de petróleo e recursos pesqueiros, o Brasil acompanhou muitos países, como os Estados Unidos, Argentina e Chile que reivindicaram os seus direitos e políticas para ampliação das áreas da plataforma continental

15 Frederico Villar (1955) também publicou o artigo A Oceanografia, os institutos científicos e a Marinha.

16 Lejeune P. H. de Oliveira, do Instituto Oswaldo Cruz, é um dos cientistas de destaque no período, cujos trabalhos sobre flora e fauna marinha nos deixam saber das iniciativas e cooperação entre instituições que merecem ser melhor investigadas. Ver suas publicações nas Memórias do Instituto Oswaldo Cruz (OLIVEIRA, 1946; 1949). 
(SOUZA et al., 2007). Os levantamentos petrolíferos no Brasil eram então terrestres, mas o conhecimento geológico da região de Campos, Rio de Janeiro, por exemplo, que continuaria a expandir-se nos anos seguintes, já sugeria a possibilidade de petróleo offshore desde os anos de 1922 (LOPES, 2019). Mais tarde a bacia de Campos se tornaria uma das maiores regiões produtoras de petróleo do país.

Mas foram os anos da Segunda Guerra que abriram um novo período de investigações sobre os oceanos. Nos Estados Unidos, as investigações sobre os oceanos ganharam um papel sem precedentes como parte integrante das estratégias de política externa dos Estados Unidos naqueles anos e no período da Guerra Fria. Essas investigações sistemáticas de ambientes de alto mar nos Estados Unidos, desde a Guerra Fria até hoje, foram tudo menos resultados "por acaso", como Naomi Oreskes (2000) salientou criticamente. E há uma enorme historiografia sobre isso, mas ainda muito a ser feito no caso brasileiro (DOMINGUES, 2005). Cabe ainda investigar a fundo e ampliar a situação dos agentes e agências em redes que tornaram as políticas sobre os oceanos viáveis no Brasil, e partilharam interesses comuns em áreas específicas do conhecimento.

No caso brasileiro, a Ictiologia, por exemplo, foi desenvolvida durante esse período sob forte influência dos Estados Unidos. Dada a falta de instituições consolidadas e específicas para a investigação oceanográfica e dada a importância da indústria pesqueira, o Museu Nacional, na década de 1940, permaneceu um lugar fundamental para a circulação de ideias e práticas científicas também para essa área de conhecimento. Ele promoveu um importante projeto de colaboração com a Universidade de Stanford, com apoio da Smithsonian Institution e do Serviço Brasileiro da Pesca. Essas instituições estavam interessadas em expandir as suas coleções, realizando inquéritos estatísticos e identificando as espécies mais pescadas para avaliar as possibilidades de expansão do comércio internacional. Heloisa Alberto Torres (1895-1977), a bem conhecida diretora do Museu Nacional, tinha então uma sólida rede de relações no governo brasileiro e em várias instituições nos Estados Unidos. Ela intermediou uma série de negociações entre os governos do Brasil e dos Estados Unidos que resultaram numa estadia de 2 anos 
(1942-1944) do ictiólogo George Sprague Myers (1905-1985), curador de Colecções Zoológicas do Museu de História Natural de Stanford (DOMINGUES, 2010; SÁ; BRITTO, 2018).

Myers realizou o primeiro inventário em grande escala dos peixes costeiros brasileiros. Foram estabelecidos pontos de recolha nos principais portos ao longo de toda a costa brasileira. Os peixes recolhidos no Museu Nacional do Rio de Janeiro foram enviados para serem identificados nos Estados Unidos, e mais tarde devolvidos, em parte, à colecção de Ictiologia do Museu Nacional. Myers ofereceu cursos e formou toda uma geração de especialistas do país. William Alonzo Gosline, formado por Myers em Stanford, também trabalhou no Museu Nacional de 1944 a 1945, catalogando as coleções do projeto (BRITTO; BUCKUP; MOREIRA, 2018).

Em outras redes de circulação, agora europeias, evidenciando fertilizações cruzadas de áreas de conhecimento e relações de amizade, Paulo Duarte (1899-1984) - o conhecido intelectual paulista criador do Instituto de Pré-História - intermediou com o amigo Paul Rivet (18761958) do Musée de l'Homme, de Paris, a contratação de Wladimir Besnard (1890-1960) para dirigir o Instituto Paulista de Oceanografia, fundado em 1946, que começou a funcionar efetivamente em 1949 e foi incorporado à Universidade de São Paulo em 1951 (MENDES, 1994; BACKX, 2013). ${ }^{17}$

Na década de 1950, o Instituto de Oceanografia da Universidade de São Paulo já fazia parte do contexto de outras tradições locais e iniciativas de cooperação internacional do pós-guerra, nas quais as atividades da Organização das Nações Unidas para a Educação, Ciência e Cultura divulgavam as perspectivas humanistas para fomentar a paz através da cooperação científica internacional. Cientistas, na sua maioria europeus, de diferentes nacionalidades, vieram à Universidade de São Paulo para a educação das elites paulistas, com uma forte ênfase na investigação científica.

17 Ver telegrama enviado por Paulo Duarte a Paul Rivet, sobre a vinda de Besnard no acervo do IO-USP, reproduzido em COMISSÃO de Memória do IOUSP. Prof. Wladimir Besnard. 1 de setembro de 1890 - 11 de agosto de 1960. São Paulo: IO-USP, 2010. p. 56. 
Com um carácter mais internacionalista adequado ao projeto maior, a equipe do Instituto foi integrada pelo islandês Ingvar Emilsson, ${ }^{18}$ especialista em oceanografia física, formado na Noruega, um país com uma longa tradição nesse campo de estudo. Outros investigadores nacionais se especializariam em química e geofísica oceânica e Marta Vannucci em oceanografia biológica. Marta Vannuchi foi a primeira oceanógrafa no Brasil, que mais tarde seria a primeira mulher a dirigir o Instituto Oceanográfico, de 1964 a 1969. Por razões políticas, ela deixou o Brasil durante os anos da ditadura militar. Marta Vannucci expandiu a sua carreira internacional na Índia e em vários outros países coordenados pela Unesco, e elaborou os estudos mais extensos sobre a importância da preservação dos manguezais no mundo, que são estudos de referência até hoje (VARELA, 2014; 2016).

A primeira expedição de que participaram pesquisadores do Instituto Paulista de Oceanografia, o mais moderno laboratório marinho da segunda metade do século XX, no país, seria novamente para as ilhas da Trindade e Martin Vaz. A expedição foi organizada pela Divisão de Oceanografia e Meteorologia Náutica da Marinha, ${ }^{19}$ suas coletas distribuídas pelos principais cientistas brasileiros e seus resultados foram publicados nos Anais Hidrográficos e no Boletim do Instituto de Oceanografia, a primeira publicação científica brasileira especializada em Oceanografia, consolidando definitivamente os estudos oceanográficos no país.

Identificada hoje como o único local no Brasil onde parte de um cone vulcânico pode ser reconhecido e em cujas águas existem nódulos polimetálicos, a Trindade é um dos locais estratégicos da Amazônia Azul. Equipes de investigadores revezam-se na ilha atualmente, em uma

18 Ingvar Emilsson (1926-2016) assumiu a direção do Instituto de 1960 a 1964, quando contratado pela UNESCO transferiu-se para Cuba e ocupou diversas posições para o desenvolvimento de estudos oceanográficos, incluindo a presidência do Conselho Latino-Americano de Oceanografia nos anos 1960.

19 Ver Gabaglia (1951). Nesse artigo ao tom da época, citando autores internacionais, o autor passa a se referir ao alcance dos trabalhos executados, não mais como de Oceanografia física, mas de Oceanografia, uma vez que os trabalhos biológicos, químicos e geológicos da área deveriam ser todos integrados. 
série de projetos com o apoio das agências de fomento, uma vez que as leis internacionais determinam que só a presença constante de cidadãos brasileiros garante ao país o direito de explorar a sua ZEE (Zona Econômica Exclusiva). Temos considerado Trindade um daqueles "sítios significantes de cognição e reflexão crítica”, proposto pelo historiador australiano das ciências Warwick Anderson (2012). Ele argumenta que há certos locais do mundo que, de forma particular e intensa, foram e podem continuar sendo focos diferenciados de pesquisas, realizadas ao longo de muitos anos, muito além de escalas locais ou regionais.

Nas décadas seguintes, quando os padrões de investigação dos oceanos foram profundamente alterados, ganhando consequentemente maior destaque nas políticas científicas e tecnológicas internacionais, incluindo o Brasil, os estudos e pesquisas sobre as ciências dos oceanos tiveram impulso com a criação, em 1951, do Conselho Nacional de Investigação, atualmente $\mathrm{CNPq}$. O CNPq foi inspirado, no contexto da Guerra Fria, nas políticas protecionistas da ciência e tecnologia com um forte apoio dos setores militares em defesa do desenvolvimento nacional da energia nuclear (ANDRADE, 1999; 2010).

Dirigido em seus primeiros anos pelo oficial da Marinha aposentado almirante Álvaro Alberto da Motta e Silva (1889-1976), desde as primeiras reuniões do $\mathrm{CNPq}$ a investigação oceanográfica e os recursos minerais da costa e do mar estiveram entre as iniciativas. $\mathrm{O}$ projeto de levantamento "aerogeológico abrangendo a faixa litorânea dos estados do Rio de Janeiro, Espírito Santo e Bahia" voltava-se para a determinação de concentrações de monazita, especialmente nas regiões das restingas do litoral fluminense e nas praias pretéritas, cujo tipo de formação sugeria argumentos geológicos a favor da existência de depósitos de monazita (CNPq, 1952, p. 35, p. 38), essenciais então, para os projetos de indústria nuclear brasileira

Desde antes da organização do CNPq, jornais e associações científicas denunciavam o conhecido contrabando de areias monazíticas uma fonte de tório e terras raras, minerais estratégicos - como lastro de navios. Os acordos secretos de exportação de monazita com enormes 
vantagens para os Estado Unidos acabaram por ser objeto de importante Comissão Parlamentar de Inquérito.

No Brasil, os estudos dos oceanos continuaram nas décadas seguintes nas mais diversas áreas disciplinares, da diplomacia à geologia, nas atividades da marinha, nos cursos e projetos de pesquisa que se organizaram nas universidades e institutos de pesquisas, centrados nas características específicas dos ambientes costeiros, ilhas, profundidades das águas oceânicas, nos chamados recursos vivos do mar e na exploração petrolífera offshore que se iniciaria no Brasil no final da década de 1960.

No início dos anos de 1970, as pesquisas oceanográficas se voltaram com maior força para os projetos de mapeamentos geológicos e geofísicos do assoalho oceânico da plataforma brasileira em convênios internacionais, como a Woods Hole Oceanographic Institution, o Lamont-Doherty Geological Observatory e o Centre National pour L'Exploitation des Océans, francês, para estudos da topografia submarina, estruturas geológicas e localização de áreas com potencial econômico para petróleo e outros recursos minerais. ${ }^{20}$

No entanto, a ênfase da investigação sobre os oceanos volta-se agora para os seus potenciais recursos minerais dos veios hidrotermais e nódulos polimetálicos, embora ainda não se tenha muito claro quais serão as perspectivas dessas políticas científicas e tecnológicas e suas consequências ambientais para o planeta, ${ }^{21}$ justamente nesses próximos anos em que a ONU discute as ciências dos oceanos.

20 RECONHECIMENTO global da margem continental brasileira. Projeto REMAC: coletânea de trabalhos técnicos, 1971 a 1975. Brasília: CPRM, 1972. Concluído em 1978, o Projeto REMAC, base para projetos atuais é considerado até hoje um dos maiores programas de pesquisas geológicas marinhas já realizado no Brasil. Entre outros estudos, o REMAC promoveu o mapeamento geológico de reconhecimento de toda a margem continental brasileira, coletando informações sobre a estrutura geológica rasa e profunda; a distribuição de sedimentos e rochas de superfície; a topografia submarina; e a localização de áreas com potencial econômico para petróleo e outros recursos.

21 Para o caso brasileiro, cabe considerar o X Plano Setorial para os Recursos do Mar. BRASIL. Decreto-lei $n^{\circ}$ 10.544, de 16 de novembro de 2020. Aprova o X Plano Setorial para os Recursos do Mar. Disponível em: < https://www.in.gov.br/en/web/dou/-/decreto-n-10.544-de-16-de-novembro-de-2020-288552390 >. Acesso em: 09 fev. 2021. 


\section{CONSIDERAÇÕES FINAIS: \\ NOVAS ETAPAS DE INVESTIGAÇÕES \\ SOBRE OS OCEANOS - NÓDULOS POLIMETÁLICOS}

Nos processos para tornar os oceanos visíveis, Jacob Hamblin (2014) lembrou que, para visualizarmos os oceanos, suas profundidades e assoalhos, cada vez mais se tornou necessário empregar novas tecnologias, instrumentos, mapas, equações. O oceano deve ser não só visível, mas também legível. Ele propõe que nós, historiadores das ciências, entendamos como os cientistas estavam (e estão) lendo e representando os oceanos em suas equações matemáticas, gráficos e tabelas. Propõe ainda problematizar como as escolhas pelos especialistas, dos instrumentos que foram ou vão ser utilizados e os dados coletados reforçam ou não o que esperavam e esperam encontrar e explorar. Mapas atuais dos assoalhos oceânicos disponibilizados em estudos científicos e particularmente pela International Seabed Authority (ISA) tornam legíveis não só como os oceanos estão sendo mapeados, catalogados, mas quadriculados e divididos em áreas de pesquisa e investimentos autorizados para consórcios internacionais de universidades, empresas e países. ${ }^{22}$

O Brasil obteve uma licença para pesquisar e futuramente explorar por 15 anos crostas de ferro-manganês, ricas em cobalto, na Elevação Rio Grande, em área internacional do Atlântico Sul, em novembro de 2015. E o número de licenças de exploração dos assoalhos oceânicos concedidos pela International Seabed Authority (ISA) tem aumentado nos últimos anos. Estão em andamento contratos por 15 anos para exploração de nódulos polimetálicos, sulfetos polimetálicos e crostas de ferro-manganês ricas em cobalto: 16 contratos para exploração de nódulos

22 Home. In: International Seabed Authority. Disponível em: <https://www.isa.org.jm/>. Acesso em: 19 ago. 2021. Sobre a elevação Rio Grande, ver, entre outros artigos e com vasta bibliografia atualizada, Santos et al. (2019). A Revista da FAPESP tem publicado sistematicamente artigos sobre as pesquisas brasileiras na Elevação Rio Grande, a exemplo do artigo com os mapas interativos no artigo de Fioravanti (2020). Assim como, por exemplo, o site do Serviço Geológico do Brasil (CPRM)/Geologia Marinha. Disponível em: <http://www.cprm.gov.br/publique/ Geologia/Geologia-Marinha/Geologia-Marinha-1122.html>. Acesso em: 09 fev. 2021. 
polimetálicos na Zona de Fratura de Clarion-Clipperton no Pacífico; 1 na Bacia Central do Oceano Índico e 1 no Oceano Pacífico Ocidental; 7 contratos para a exploração de sulfetos polimetálicos nas regiões Central e Sudoeste do Oceano Índico e Centro-Atlântica, e 5 contratos para a exploração de crostas ricas em cobalto no Oceano Pacífico Ocidental. ${ }^{23}$

Os nódulos polimetálicos do assoalho oceânico foram coletados pela primeira vez em 1873, perto do sudoeste da ilha de Ferro, nas Canárias, na viagem da Challenger. Ao longo dos anos, grandes quantidades de nódulos foram recuperadas dos oceanos Atlântico, Índico e Pacífico e, no final dos anos 1950, investigadores norte-americanos analisaram a rentabilidade da exploração desses depósitos (MERO, 1959). A Primeira Conferência das Nações Unidas sobre o Direito do Mar, em 1958, a UNCLOS tinha como um dos seus principais objetivos regular a exploração desses recursos do fundo dos oceanos. Essas concentrações de manganês, cobalto, níquel, cobre e uma gama variada de minerais ocorrem nos assoalhos oceânicos entre 4.000 a 5.000 metros de profundidade e em substratos datados de 20 a 80 milhões de anos, com processos de deposição lentíssimos, ou diretamente pela água do mar, ou em processos diagenéticos associados a atividades biológicas dos fluidos hidrotermais.

Além dos nódulos polimetálicos, outros recursos dos oceanos são os veios hidrotermais associados às atividades vulcânicas das cadeias meso-oceânicas e bordas de placas tectônicas, que abrigam comunidades bentônicas que sobrevivem em ambientes sulfetados e sem qualquer luz. Os veios hidrotermais já eram conhecidos nos estudos sobre tectônica das placas, mas até os anos de 1970 não se conhecia ainda sua importância e significado geoquímico, nem os ecossistemas a eles associados (MELLO; QUENTAL, 2000; ZENG; ALAIN; ZONGZE, 2021). Só até os anos de 1990, cerca de 300 novas espécies haviam sido identificadas e novas famílias taxonômicas foram criadas (TUNNICLIFFE, 1991). Em média, duas novas espécies têm sido descritas a cada mês, nos últimos 25 a 30 anos (RAMIREZ-LLODRA; SHANK; GERMAN 2007).

23 EXPLORATION Contracts. In: International Seabed Authority. Disponível em: <https://www. isa.org.jm/index.php/exploration-contracts>. Acesso em: 9 fev. 2021. 
Cientistas, governos e empresas interessadas nessas explorações discutem não só a importância desses investimentos, como a possibilidade de exploração desses recursos com baixos impactos ambientais, enquanto outros alertam para suas ameaças à biodiversidade pouco conhecida (HEIN; KOSCHINSKY; KUHN, 2020). Os estudos também dos historiadores e sociólogos das ciências sobre esses projetos e recursos minerais associados a organismos e micro-organismos podem ser cruciais para reflexões sobre esses impactos.

As ciências dos oceanos reúnem tradições que provêm das mais diferentes áreas disciplinares: hidrografia do século XIX, História Natural, Geografia, pesca, Biologia, Química, Geologia, Oceanografia matemática e dinâmica pós-Segunda Guerra Mundial e a sua relação com as Ciências Ambientais contemporâneas, para além da História e da Política. Trata-se de buscar, também no país, quadros mais amplos de como os complexos campos de investigação atuais foram forjados, alterados ao longo do tempo, entrelaçados e, nesses processos, constituíram novos interesses, novas tecnologias, novas comunidades diversificadas e enormemente especializadas.

A procura de tais quadros enquadra-se nas perspectivas das histórias das culturas científicas das últimas décadas, como James Secord (2004) e Gregory Good (2000) sugeriram, recuperando os significados das práticas comunitárias das ciências, menos segregadas em quaisquer das disciplinas, e mais amplamente consideradas através da circulação dos conhecimentos, informações, objetos e redes que articulam as práticas dos especialistas com uma série de outros atores sociais. Os processos de prospecção dos recursos dos oceanos são complexos, exigem superar fronteiras, superar antigos quadros disciplinares e, para tal, abordagens históricas podem dar suas contribuições.

A produção sobre aspectos da história das ciências dos oceanos no Brasil é recente e já estamos, desde há alguns anos, em uma outra etapa da exploração dos oceanos, com minerações instaladas em profundidades oceânicas, cuja biodiversidade está sendo perdida e os impactos dessas minerações são praticamente desconhecidos. A construção das ciências dos oceanos no Brasil foi e está claramente integrada nas redes 
internacionais de circulação de diferentes interesses, conhecimentos e complexidades de relações pessoais, institucionais e governamentais. Talvez uma das questões mais prementes que a Década das Ciências dos Oceanos das Nações Unidas poderia enfrentar no país seria ampliar a discussão sobre as políticas técnico-científicas, as ações, projetos e experiências em andamento, deslocando fronteiras, criando redes, incluindo a história e os estudos sociais de ciências e tecnologias.

\section{Agradecimentos}

A autora agradece a leitura e as observações sobre o texto das pesquisadoras Alda L. Heizer, Irina Podgorny e Silvia F. de M. Figueirôa, e ao CNPQ por seu apoio aos projetos de pesquisa: Produtividade em Pesquisa -1D. CNPq 2015-2019. Oceanos: capítulos estratégicos na História das ciências geológicas (1870-1950). Projeto n. 303505/2018-4. PQ-1C /CNPQ 2019-2023 - Pesquisas paleontológicas: base para a busca de petróleo no Brasil (1907-1940).

\section{REFERÊNCIAS BIBLIOGRÁFICAS}

AB'SABER, Aziz N. Geociências. In: FERRI, Mário Guimarães; MOTOYAMA, Shozo (coords.). História das ciências no Brasil. São Paulo: EPU, 1979-1980. p. 117-205.

ALVES, Francisco das N. A Política exterior brasileira à época da Velha República: a questão da ilha da Trindade. BIBLOS, v. 13, p. 105-112, 2001. ANDERSON, Warwick. Hybridity, Race, and Science: the Voyage of the Zaca, 1934-1935. Isis, v. 103, n. 2, p. 229-253, June 2012.

ANDRADE, Ana M. R. de. Físicos, mésons e política: a dinâmica da ciência na sociedade. São Paulo: HUCITEC/MAST-CNPq, 1999.

ANDRADE, Ana M. R. de. Valores e ideais presentes nas fundações do CBPF e CNPq. In: TROPER, Amós; VIDEIRA, Antonio; LEITE, Cássio Vieira (orgs.). Os 60 anos do CBPF e a gênese do CNPq. Rio de Janeiro: CBPF, 2010. p. 27-57. 
BACKX, Isabela. Paul Rivet e Paulo Duarte: discursos sobre humanismo e Arqueologia no Brasil. Dissertação (Mestrado em História) - Universidade Estadual de Campinas, Campinas, 2013.

BARRIGA, Fernando José Arraiano de Sousa. Ciência e recursos naturais debaixo do mar profundo. In: MESQUITA, Mário; VICENTE, Paula (orgs.). O Mar na história, na estratégia e na ciência. Lisboa: Fundação Luso-Americana/Tinta da China, 2013. p. 187-196.

BENSON, Keith R.; REHBOCK, Philip F. (orgs.). Oceanographic History: the Pacific and Beyond. Seattle; London: University of Washington Press, 2002.

BENTES FILHO, Giovanni Roberto Protásio. Do Norte ao Sul: a missão do cruzador José Bonifácio e a incorporação do pescador a um projeto de nação (1900-1930). Dissertação (Mestrado em História) - Universidade Federal do Rio Grande do Norte, Natal, 2018.

BRITTO, Marcelo R; BUCKUP, Paulo A; MOREIRA, Cristiano R. Gosline e a coleção Ictiológica do Museu Nacional. In: SÁ, Magali Romero; BRITTO, Marcelo R. (orgs.). A Cooperação científica Brasil-Estados Unidos na Segunda Guerra Mundial: levantamento dos peixes marinhos brasileiros de importância comercial (1943-1955). Rio de Janeiro: FAPERJ; Ideia D., 2018. p. 77-99.

BURSTYN, Harold L. Science Pays Off: Sir John Murray and the Christmas Island Phosphate Industry, 1886-1914. Social Studies of Science, v. 5, n. 1, p. 5-34, 1975.

CALLOU, Angelo Brás Fernandes. A Voz do Mar. Construção simbólica da realidade dos pescadores brasileiros pela missão do cruzador José Bonifácio. XVIII Congresso Brasileiro de Ciências da Comunicação: INTERCOM, 1995, Aracajú. Anais... Aracajú: Universidade Federal de Sergipe, 1995. p. 1-18.

COSTA, Eurico. Discurso de Posse. Revista da Sociedade de Geografia do Rio de Janeiro, v. 2, t. XLIII, p. 165-168, 1936.

CNPq. Retrospecto das atividades do Conselho Nacional de Pesquisas no campo das pesquisas científicas e tecnológicas, no ano de 1951. Rio de Janeiro: CNPq, 1952. 
DEACON, Margaret. Scientists and the Sea 1650-1900. Aldershot; Brookfield: Ashgate, 1997.

DOMINGUES, Heloisa Maria Bertol. Heloisa Alberto Torres e o inquérito sobre as ciências naturais e antropológicas, 1946. Boletim do Museu Paraense Emílio Goeldi. Ciências Humanas, v. 5, n. 3, p. 625-643, 2010.

DUARTE, Regina Horta; HORTA, Güydo Campos Machado Marques. Barth and Trindade Island, 1957-1959. História, Ciência, SaúdeManguinhos, v. 19, n. 3, p. 951-968, 2012.

FIGUEIRÔA, Silvia Fernanda de Mendonça. Brazilian Geology for Brazilian Students: the General Geology Textbook published by John Casper Branner in 1906. Earth Sciences History, v. 35, n. 2, p. 375-386, 2016.

FIGUEIRÔA, Silvia Fernanda de Mendonça. A Sample of Geological textbooks: the Book História Física da Terra (1943) by Alberto Betim Paes Leme. Almagest, v. 3, p. 106-121, 2012.

FIORAVANTI, Carlos. As Montanhas submersas do Brasil. Levantamentos submarinos identificam dezenas de montes no fundo do mar, alguns com até 4 mil metros de altura. Revista Pesquisa FAPESP, fev. 2020.

FROTA, Fernando Saldanha da Gama. O Serviço hidrográfico da Marinha. Revista da Sociedade de Geografia do Rio de Janeiro, v. 2, t. XLIII, p. 169-178, 1936.

GABAGLIA, João Raja. Relatório. Divisão de oceanografia e meteorologia náutica da Marinha. Revista Marítima Brasileira, v. LXX, n. 789, p. 541-549, jan.-mar. 1951.

GOOD, Gregory A. The Assembly of Geophysics: Scientific Disciplines as Frameworks of Consensus. Studies in the History and Philosophy of Modern Physics, v. 31, p. 259-292, 2000.

HAMBLIN, Jacob D. Seeing the Oceans in the Shadow of Bergen Values. Isis, v. 105, n. 2, p. 352-363, 2014.

HEIN, James R; KOSCHINSKY, Andrea; KUHN, Thomas. Deep-ocean Polymetallic Nodules as a Resource for Critical Materials. Nature Reviews Earth \& Environment, v. 1, p. 158-169, 2020.

HEIZER, Alda; LOPES, Maria Margaret; GARCÍA, Susana. Carta das editoras convidadas. Histórias, ciências e políticas de oceanos e mares. 
Revista História, Ciência, Saúde-Manguinhos, v. 21, n. 3, p. 803-804, jul.-set. 2014.

KOFOID, Charles Atwood. The Biological Stations of Europe. Bulletin, n. 4, p. 1-6, 1910.

KOHLER, Robert E. Landscapes and Labscapes: exploring the Lab-field Border in Biology. Chicago; London: The University of Chicago Press, 2002. LIVINGSTONE, David N. Putting Science in its Place. Geographies of Scientific Knowledge. Chicago: University of Chicago Press, 2003.

LOBO, Bruno Ilha da Trindade. Conferência feita na Bibliotheca Nacional, no dia 18 de julho de 1918. Archivos do Museu Nacional do Rio de Janeiro, v. XXII, p. 105-156, 1919.

LOPES, Maria Margaret. Oceanos: da Social Studies of Sciences à Revista Marítima. In: Simpósio Nacional de Ciência, Tecnologia e Sociedade, VII ESOCITE.BR-TECSOC, 2017, Brasília. Anais... Brasília: ESOCITE. BR, 2017. p. 1-18.

LOPES, Maria Margaret. The Challenger Deep Sea Expedition (1872-1876) in Brazil. Viaggiatori, v. 1, p. 118-132, 2018.

LOPES, Maria Margaret. Petroleum: New Energy Perspectives for Brazil in 1922. In: FIGUEIRÔA, Silvia Fernanda; GOOD, Gregory A; PEYERL, Drielli (orgs.). History, Exploration \& Exploitation of Oil and Gas. Historical Geography and Geosciences. Cham: Springer, 2019. p. 25-36.

LOPES, Maria Margaret; PODGORNY, Irina. Entre mares e continentes: aspectos da trajetória científica de Hermann von Ihering, 1850-1930. História, Ciências, Saúde-Manguinhos, v. 21, n. 3, p. 809-826, 2014.

LOPES, Maria Margaret; NUNES, Maria de Fátima; PINA, Madalena Esperança. Cruzando fronteiras: a construção de uma tradição para o 1. ${ }^{\circ}$ Congresso Nacional de Ciências Naturais, Lisboa, 1941. In: FITAS, Augusto José dos Santos et al (orgs.). A Actividade da Junta de Educação Nacional. Lisboa: Cehfci/Caleidoscópio, 2012. p. 115-132.

MELLO, Sidney L. M; QUENTAL, Sandra H. A. J. Depósitos de sulfetos metálicos no fundo dos oceanos. Revista Brasileira de Geofísica, v. 18, n. 3, p. 411-430, 2000.

MENDES, Erasmo Garcia. Paulo Duarte. Estudos Avançados, v. 8, n. 22, p. 189-193, 1994. 
MERO, John L. The Mining and Processing of Deep-sea Manganese Nodules. Berkeley: Institute of Marine Resources, 1959.

MURRAY, John. Report on the Scientific Results of the Voyage of H.M.S. Challenger During the Years 1873-76 under the Command of Captain George S. Nares and the late Captain Frank Tourle Thomson. Prepared under the Superintendence of the late Sir C. Wyville Thomson and Now of John Murray. Published by Order of Her Majesty's Government. Hanover: David C. Bossard, 2004. Disponível em: < http:// www.19thcenturyscience.org/HMSC/HMSC-INDEX/index-illustrated. htm >. Acesso em: 09 fev. 2021.

OLIVEIRA, Lejeune P. H. de. Estudos sôbre o Micropláncton capturado durante a viagem do navio hidrográfico Lahmeyer nas baías de Ilha Grande e Sepetiba. Memórias do Instituto Oswaldo Cruz, v. 44, n. 3, p. 441-488, 1946.

OLIVEIRA, Lejeune P. H. de. Relatório sobre excursões científicas feitas a bordo do navio Hidrográfico Rio Branco, sob a orientação do professor Piérre Drach, da Sorbonne. Memórias do Instituto Oswaldo Cruz, v. 47, n. 1-2, p. 87-96, 1949.

ORESKES, Naomi. Getting Oceanography Done. Earth Sciences History, v. 9, n. 1, p. 36-43, 2000.

PAES LEME, Alberto B. História física da Terra: vista por quem a estudou no Brasil. Rio de Janeiro: F. Briguiet \& Cia, 1943.

PINNA, Armando. Curso de Oceanografia, pesca e psicultura. Rio de Janeiro: Departamento de Estatística e Publicidade, 1938.

RAJ, Kapil. Beyond Postcolonialism ... and Postpositivism: Circulation and the Global History of Science. Isis, v. 104, n. 2, p. 337-347, June 2013.

RAMIREZ-LLODRA, Eva; SHANK, Timothy M; GERMAN, Christopher R. Biodiversity and Biogeography of Hydrothermal Vent Species: Thirty Years of Discovery and Investigations. Oceanography, v. 20, n. 1, p. 30-41, 2007.

RECONHECIMENTO global da margem continental brasileira. Projeto REMAC: coletânea de trabalhos técnicos, 1971 a 1975. Brasília: CPRM, 1972. ROBERTS, Lissa. Situating Science in Global History: Local Exchanges and Networks of Circulation. Itinerario, v. 33, n.1, p. 9-30, mar. 2009. 
ROZWADOWSKI, Helen M. The Sea Knows no Boundaries: a Century of Marine Science under ICES. Seattle; London: University of Washington Press and International Council for the Exploration of the Sea, 2002. ROZWADOWSKI, Helen M. Fanthoming the Ocean. The Discovery and Exploration of the Deep Sea. Cambridge; London: Harvard University Press, 2008.

SÁ, Magali Romero; BRITTO, Marcelo R. (orgs.). A Cooperação científica Brasil-Estados Unidos na Segunda Guerra Mundial: levantamento dos peixes marinhos brasileiros de importância comercial (1943-1955). Rio de Janeiro: FAPERJ; Ideia D, 2018.

SANTOS, Roberto Ventura, et al. Dating Gondwanan Continental Crust at the Rio Grande Rise, South Atlantic. Terra Nova, v. 31, n. 9, p. 1-6, May 2019.

SECORD, James A. Knowledge in Transit. Isis, v. 95, n. 4, p. 654-672, Dec. 2004.

SECÇÃO de Navegação e Hydrografia. Barão de Teffé. Revista do Instituto Polytechnico Brasileiro, t. XVIII, p. 151-152, 1888.

SEIDL, Roberto. Oceanographia. Revista da Sociedade de Geografia do Rio de Janeiro, t. XXXI, p. 104-129, 1926-1927.

SOUZA, Kaiser Gonçalves de, et al. Aspectos políticos-estratégicos dos recursos minerais da área internacional dos oceanos. Parcerias Estratégicas, v. 12, n. 24, p. 95-114, 2007.

SVANSSON, Artur W. Theoretical Oceanographer. Earth Sciences History, v. 29, n. 1, p. 100-120, 2010.

TUNNICLIFFE, Verena. The Biology of Hydrothermal Vents: Ecology and Evolution. Oceanography and Marine Biology: An Annual Review, v. 29, p. 319-407, 1991.

VARELA, Alex Gonçalves. O Instituto Oceanográfico da Universidade de São Paulo: um capítulo do processo de emergência e consolidação das ciências oceanográficas no Brasil, 1946-1969. História, Ciências, SaúdeManguinhos, v. 21, n. 3, p. 951-969, 2014.

VARELA, Alex Gonçalves. Os textos da cientista Marta Vannucci sobre o plâncton no Instituto Oceanográfico da Universidade de São Paulo (1946-1969). Cadernos Pagu, v. 48, p. 1-24, 2016. 
VILLAR, Frederico. Os Serviços da pesca no Brasil. As colônias de pescadores na defesa nacional. Revista Marítima Brasileira, v. LXX, n. 1-3, p. 47-70, 1950.

VILLAR, Frederico. A Oceanografia, os institutos científicos e a Marinha. Revista Marítima Brasileira, v. LXXIV, n. 7-9, p. 173-180, 1955.

WISE, M. Norton. Making Visible. Focus: Science and Visual Culture. Isis, v. 97, n. 1, p. 75-82, Mar. 2006.

ZENG, Xiang; ALAIN, Karine; ZONGZE, Shao. Microorganisms from Deep-Sea Hydrothermal Vents. Marine Life Science \& Technology, v. 3, n. 2, p. 204-230, Jan. 2021.

ZUROSKI, Emma. Situating the Local in a Global Expedition: HMS Challenger Expedition in New Zealand, 1874. Journal of the Royal Society of New Zealand, v. 47, n. 1, p. 107-111, 2017. 